\title{
Postpartum atypical haemolytic uremic syndrome: a rare clinical entity
}

\author{
Aanchal Sablok $^{1}$, Taru Gupta ${ }^{1 *}$, Sangeeta Gupta $^{1}$, R. K. Duggal ${ }^{2}$, Amrita Tiwari $^{1}$ \\ ${ }^{1}$ Department of Obstetrics and Gynecology, ESI-PGIMSR, Basaidarapur, New Delhi, India \\ ${ }^{2}$ Consultant and Head of Dialysis Unit, Department of Nephrology, ESI-PGIMSR, Basaidarapur, New Delhi, India
}

Received: 26 May 2019

Accepted: 02 July 2019

*Correspondence:

Dr. Taru Gupta,

E-mail: tarugupta1971@yahoo.com

Copyright: ( ) the author(s), publisher and licensee Medip Academy. This is an open-access article distributed under the terms of the Creative Commons Attribution Non-Commercial License, which permits unrestricted non-commercial use, distribution, and reproduction in any medium, provided the original work is properly cited.

\begin{abstract}
P-aHUS has incidence of 1 in 25000 pregnancies. It's characterized by microangiopathic haemolytic anemia, thrombocytopenia and renal failure. Mrs X, 26 year old lady, G2 P1L1 with 39 weeks POG came to emergency of a tertiary care hospital. She underwent LSCS in view of previous caesarean section not willing for trial of labour. Antenatal, intrapartum and immediate post operative period were uneventful. However, she became anuric 36 hours post operatively. Laboratory investigations suggested hemolysis. Complement system evaluation showed decreased complement levels. Diagnosis of p-aHUS was made by taking multidisciplinary approach and renal biopsy. Patient received 4 sessions of plasmapheresis and symptomatic treatment. Gradually her urine output increased and she was discharged with the baby on post operative day 19. Diagnosis of p-aHUS is tricky owing to similar clinical features with many other pregnancy associated conditions. Timely management and diagnosis are imperative to save the mother's life.
\end{abstract}

Keywords: Complement system, Haemolytic uremic syndrome, Postpartum, Pregnancy, Plasmapheresis, Thrombocytopenia

\section{INTRODUCTION}

Haemolytic uremic syndrome (HUS) was first described by Gasser in 1955 in children in whom it occurs in a milder form. ${ }^{1}$ The pathophysiology of haemolytic uremic syndrome is very much similar to thrombotic thrombocytopenic purpura (TTP) which is characterized by a pentad of thrombocytopenia, haemolytic anaemia, fever, neurological abnormalities and renal impairment. ${ }^{2}$ Commonly, the triggering factor leading to the onset of HUS is an infection caused by Escherichia coli. Clinically also, HUS is similar to TTP, but the microvascular injury mainly affects the kidneys.

Atypical HUS (aHUS) is characterized by microangiopathic haemolytic anaemia, thrombocytopenia and acute kidney injury that are not related to Escherichia coli. If left undiagnosed and untreated, aHUS can be life threatening and can lead to disastrous consequences. aHUS constitutes $5-10 \%$ of all cases of adult HUS. aHUS when occurs in pregnancy, universally in the postpartum period (<10weeks), it is called as pregnancy associated HUS (p-aHUS). It is known to occur in 1 in 25000 pregnancies and is associated with a poor maternal outcome. $^{3,4}$

Clinically pregnancy associated aHUS has symptoms similar to other pregnancy associated conditions like Pre eclampsia, AFLP, TTP making the diagnosis very tricky. We here describe a rare case of pregnancy associated HUS (p-aHUS) in an attempt to help the reader to differentiate between these similar symptomatic 
conditions for better patient management and timely intervention.

\section{CASE REPORT}

All the information of the patient shared in this study was done after obtaining the required consent from the patient.

Mrs X, 26 year old lady came to the emergency obstetric wing of a tertiary care centre in north India with the diagnosis of G2 P1L1 with 39 weeks POG in labour with history of previous caesarean section 5 years back in view of non progress of labour. She was married for the past 6 years and has had regular antenatal checkups. Her previous pregnancy and the present antenatal status were uneventful with no history suggestive of pre-eclampsia or gestational diabetes mellitus. There was no relevant past medical, surgical or family history.

She underwent emergency caesarean section in view of previous caesarean section not willing for trial of labour. The patient delivered a female baby of weight $2.75 \mathrm{~kg}$. Intra-partum and immediate postpartum period was uneventful. However, after 24 hours post caesarean section, she developed a sudden decrease in urine output leading to anuria in the next 6 hours. There was no history of headache, blurring of vision, epigastric pain or antihypertensive medication intake. No history of diarrhoea, fever, skin rash, confusion, convulsion or focal neurological deficit. There was no history of jaundice, anorexia, malaise, nausea and history of renal disease or other systemic illness in past.

Table 1: Pre operative and post operative biochemical profile.

\begin{tabular}{|lll|}
\hline $\begin{array}{l}\text { Biochemical laboratory } \\
\text { parameters }\end{array}$ & $\begin{array}{l}\text { Pre } \\
\text { operative }\end{array}$ & $\begin{array}{l}36 \text { hour post } \\
\text { operative }\end{array}$ \\
\hline Liver function test & 0.8 & 1.6 \\
\hline Total bilirubin & 0.2 & 0.4 \\
\hline Direct bilirubin & 0.6 & 1.2 \\
\hline Indirect bilirubin & 27 & 89 \\
\hline SGOT & 28 & 95 \\
\hline SGPT & 291 & 315 \\
\hline SALP & & \\
\hline Kidney function test & 26 & 113 \\
\hline Serum urea & 0.6 & 5.3 \\
\hline Serum creatinine & & \\
\hline Serum electrolytes & $135 \mathrm{meq} / \mathrm{L}$ & $130 \mathrm{meq} / \mathrm{l}$ \\
\hline Serum sodium & $4 \mathrm{meq} / \mathrm{L}$ & $3.5 \mathrm{meq} / \mathrm{L}$ \\
\hline Serum potassium & 9 & 8.8 \\
\hline Serum calcium & & 946 \\
\hline Serum Lactic dehydrogenase & WNL \\
\hline Coagulation profile & & \\
\hline Immunology & & $37(50-90)$ \\
\hline C3 level & & $31(10-40)$ \\
\hline C4 level & & Negative \\
\hline ANA & & \\
\hline APLA & & \\
\hline \multicolumn{2}{l}{} & \\
\hline
\end{tabular}

Table 2: Differentiating features between similar clinical conditions. ${ }^{10}$

\begin{tabular}{|c|c|c|c|c|}
\hline Clinical features & HELLP & AFLP & TTP & P-aHUS \\
\hline Time of onset & $3^{\text {rd }}$ trimester & $3^{\text {rd }}$ trimester & $2^{\text {nd }}$ and $3^{\text {rd }}$ trimester & Postpartum \\
\hline Recovery after delivery & Yes & Yes & No recovery & No recovery \\
\hline $\begin{array}{l}\text { Unique clinical } \\
\text { manifestation }\end{array}$ & $\begin{array}{l}\text { High blood pressure } \\
\text { and } \pm \text { proteinuria }\end{array}$ & $\begin{array}{l}\text { Jaundice, nausea, } \\
\text { vomiting }\end{array}$ & Neurological symptoms & Kidney involvement \\
\hline Acute kidney injury & Mild/moderate & Moderate & Mild/moderate & Severe \\
\hline \multicolumn{5}{|l|}{ Clinical signs/ symptoms } \\
\hline Hypertension & + & \pm & \pm & + \\
\hline Jaundice & \pm & ++ & \pm & \pm \\
\hline Nausea/vomiting & \pm & ++ & + & + \\
\hline Purpura & - & - & + & - \\
\hline Neurological finding & - & - & + & - \\
\hline Fever & - & - & + & - \\
\hline \multicolumn{5}{|l|}{ Lab findings } \\
\hline Haemolytic anemia & + & \pm & ++ & + \\
\hline Coagulopathy & \pm & ++ & - & - \\
\hline Hypoglycemia & - & ++ & - & - \\
\hline Thrombocytopenia & More than 20000 & More than 50000 & Less than 20000 & More than 20000 \\
\hline LDH level & 600 or more & Variable & More than 1000 & More than 1000 \\
\hline Elevated bilirubin & \pm & + & + & NA \\
\hline $\begin{array}{l}\text { Liver transaminase } \\
\text { derangement }\end{array}$ & + & ++ & 0 & 0 \\
\hline Vwf multimers & 0 & 0 & + & + \\
\hline ADAMTS $13<10 \%$ & 0 & 0 & ++ & + \\
\hline
\end{tabular}


On general physical examination, she was found to have facial puffiness. Rest of the general and systemic examination was within normal limits. On evaluating the patient, it was found that her haemogram had dropped from $11.1 \mathrm{gm} / \mathrm{dl}$ to $6.7 \mathrm{gm} / \mathrm{dl}$ and her platelets had dropped from $1.6 \mathrm{lakh} / \mathrm{mm}^{3}$ to $34000 / \mathrm{mm}^{3}$, 36 hours post operatively. As the blood picture was indicative of hemolysis, peripheral smear was done which showed shistocytes with a rectic count of $3 \%$. Haemoglobin electrophoresis was normal and direct combs test was negative. Urine analysis was also done which was normal. It was found that 36 hours post operatively her liver function test as well kidney function test had become deranged. Table 1, gives the picture of her change in LFT and KFT and other biochemical profile.

Ultrasound KUB was also done as a part of kidney function profile test which showed bilateral normal size kidneys with thickened parenchyma and enhanced cortical echogenicity.

As the laboratory and radiological picture showed hemolysis with parenchymal kidney changes, the differential diagnosis of pre eclampsia, HELLP syndrome were first made but as her blood pressure throughout her antenatal, intra-partum and post partum period was within normal range, the diagnosis of PE and HELLP was ruled out.

Complement level evaluation was made because of the presence of schistocytes on the peripheral smear and after having a multidisciplinary approach of involving a nephrologist. As her blood pressure was normal and the complement system has shown a decrease in complement levels, a differential diagnosis of TTP and aHUS was also made. The clue to the diagnosis of aHUS was a decrease in the complement system level and the non involvement of the neurological system. Renal biopsy was done which was suggestive of thrombotic microangiopathy (HUS). However, due to laboratory limitations genetic testing could not be done.

The patient finally received supportive management and four sessions of plasmapheresis. Gradually her renal function improved. She was discharged on post-operative day 19 with $\mathrm{Hb}-10.2 \mathrm{gm} \%$, platelet count $-1.3 \mathrm{lac} / \mathrm{mm}^{3}$, serum creatinine $1.4 \mathrm{mg} / \mathrm{dl}$ and urine output more than 1.5 litre/ 24 hours. She is still on follow up and is doing fine.

\section{DISCUSSION}

Various pathogenic mechanisms have been postulated leading to the endothelial cell insult that occurs in HUS. This could be due to verotoxin induced cell injury in shiga toxin-induced HUS, complement system dysregulation as occurs in atypical HUS. Various other, more or less well defined patterns of endothelial cell lesions in the heterogenous group of secondary HUS associated with autoimmune diseases, infections, drugs and pregnancy. ${ }^{2}$

Clinically HUS is similar to TTP. TTP can be congenital or acquired.

ADAMTS13 is a von Willebrand factor-cleaving metalloprotease that prevents the circulation of unusually large von Willebrand's factor multimers. This enzyme is produced mainly in the liver and is markedly reduced ( $<5 \%$ of normal) in most patients with congenital TTP, and antibodies that neutralize ADAMTS13 have been found in women with acquired TTP. Pregnancy carries a high risk for ADAMTS13 deficiency-associated thrombotic thrombocytopenic purpura, but also HUS. ${ }^{5,6}$

Atypical HUS accounts for $5-10 \%$ of HUS and is a rare life threatening condition as mentioned before. When pregnancy triggers thrombotic microangiopathy, it is referred to as pregnancy associated atypical haemolytic uremic syndrome ( $p$ aHUS). It is atypical as there is no association with Escherichia coli and occurs due to complement system dysregulation and the triggering factor being pregnancy. This occurs in 1-25000 pregnancy and is associated with high morbidity and mortality is left undiagnosed. Mostly this occurs in the postpartum period and is associated with a poor maternal outcome. $^{7,8}$ In a French cohort, $60-70 \%$ developed end stage renal disease. ${ }^{9}$

\section{Diagnosis}

\section{Clinical presentation of $p$ - aHUS}

Patients generally present with facial puffiness, edema, and high blood pressure, oliguria ultimately leading to anuria and kidney failure. In some cases, patients might have flu like prodromal phase. It is quite challenging to diagnose $\mathrm{p}$-aHUS in the postpartum period as it has symptoms mimicking other clinical conditions such as HELLP (hemolysis, elevated liver enzymes and low platelets), TTP, AFLP (acute fatty liver of pregnancy). However, no matter how difficult the diagnosis it is imperative to come to the right definitive diagnosis and timely intervention to prevent maternal mortality.

Apart from clinical symptoms there are differentiating laboratory findings that help in the diagnosis of p-aHUS. Table 2: Gives brief differentiating features between this clinical conditions. ${ }^{10}$

\section{Role of complement system}

p-aHUS is a severe systemic disease owing to the dysregulation of complement system in the body. Mutations in one or more genes coding for proteins that cause complement system regulation have been established as a risk factor for aHUS. Three distinct pathways (classical, lectin and the alternative pathway) have been known to be involved in the activation of 
complement cascade that lead to the generation of $\mathrm{C} 3$ convertases. It is presumed that a lack of control of the alternative pathway that leads to the formation of $\mathrm{C} 3$ convertases ultimately leads to the complement induced lesions of the host cells, mainly the endothelial cells in the kidneys. Acquired (anti-FH antibodies) or constitutional (inactivating mutations in FH, FI, or MCP coding genes or activating mutations in factor $\mathrm{B}$ and $\mathrm{C} 3$ coding genes) dysregulation of the alternative $\mathrm{C} 3$ convertase has been established as a risk factor for the occurrence of aHUS. ${ }^{9}$

As there is over activation of complement system, on laboratory evaluation the levels protein $\mathrm{C} 3$ are found to be decreased as was seen in the present case.

A study conducted by Fakhouri et al in studied the presentation and outcome of patients presenting with paHUS and the prevalence of alternative C3 convertase dysregulation. ${ }^{6}$ They found that P-aHUS occurred in 21 of the 100 adult female patients with atypical HUS, with $79 \%$ presenting postpartum and found complement abnormalities in 18 of the 21 patients. The outcomes were poor: $62 \%$ reached ESRD by 1 month and $76 \%$ by last follow-up. The risk for P-aHUS was highest during a second pregnancy. Thirty-five women, 26 (74\%) of whom had complement abnormalities, had at least one pregnancy before the onset of a non-pregnancy-related aHUS. Outcomes did not differ between patients with pregnancy-related and non-pregnancy-related aHUS. Mutations in the SCR19-20 domains of factor $\mathrm{H}$ were less frequent in P-aHUS patients compared with nonpregnancy-related aHUS. Finally they concluded that better understanding of complement dysregulation in pregnancy complications is essential, especially to guide development of pharmacologic agents to modulate this system.

\section{Treatment}

The treatment of aHUS is similar to TTP. As there is unregulated activation of the complement system, removal of the lesions of the complement system is the mainstay. This is achieved by either plasma exchange (PE) or by plasmapheresis. Owing to the devastating nature of the disease, PE should start as soon as the diagnosis is made and one should not wait for genetic testing or testing for other factors like ADAMTS 13.2 A multidisciplinary team approach is to be made consisting of maternal -fetal medicine specialist, haematologists and transfusion medicine specialists in dealing with these patients.

Duration of PE is usually individualized and should be continued until complete normalization of the blood parameters (platelets $>150,000 / \mathrm{mm}^{3}$ for 2 consecutive days and no evidence of hemolysis). In general, failure of $\mathrm{PE}$ is considered when there is persistent thrombocytopenia or worsening clinical status despite intervention. To enhance recovery, a combination of plasma exchange and prednisone at $1 \mathrm{mg} / \mathrm{kg} / \mathrm{day}$ is frequently used as in non-pregnant protocols. The rate of plasma exchange may be reduced when recovery starts and the dose of prednisone tapered down to $5 \mathrm{mg} /$ day and maintained at this dose until 3 weeks postpartum. Thereafter, the prednisone can be completely tapered off. ${ }^{2}$

\section{Role of eculizumab}

Eculizumab is a humanized recombinant monoclonal antibody that inhibits the terminal pathway of complement activation by blocking the activation of complement protein C5. Recent evidence suggests that eculizumab increased platelet counts, improved renal function, decreased the need for renal replacement therapy, and improved overall quality of life 11 in patients suffering from $\mathrm{p}$-aHUS. The latter has led the Food and Drug Administration (FDA) to approve eculizumab as the treatment for aHUS in the United States. As this medicine is very expensive it is not freely available in India especially in the government sector.

\section{CONCLUSION}

- The diagnosis of p-aHUS is quite challenging as the symptoms often mimic other pregnancy associated conditions like PE, AFLP.

- Coming to the correct diagnosis is imperative as, if left undiagnosed and untreated the maternal mortality is quite high.

- The correct diagnosis and timely intervention by utilizing a multidisciplinary team approach is the key to save a patient's life.

- Management involves prompt plasmapheresis and supportive management. Eculizumab is the new drug which can be used if available.

Funding: No funding sources

Conflict of interest: None declared

Ethical approval: Not required

\section{REFERENCES}

1. Gasser C, Gautier E, Steck A, Siebenmann RE, Oechslin R. Hemolytic-uremic syndrome: bilateral necrosis of the renal cortex in acute acquired haemolytic anemia. Schweiz Med Wochenschr. 1955;85(38-39):905-9.

2. Vidaeff AC, Ramin SM. Renal disorders in High risk pregnancy management options, fourth edition, ed. James D, Steer PJ, Weiner CP, Gonik B, Crowther CA, Robson SC, St. Louis. Elsevier Saunders; 2011:913-935.

3. Dashe JS, Ramin SM, CunninghamFG. The longterm consequences of thrombotic microangiopathy (thrombotic thrombocytopenic purpura and hemolytic uremic syndrome) in pregnancy. Obstet Gynecol. 1998;91(5, Pt 1):662-8. 
4. Noris M, Remuzzi G. Hemolytic uremic syndrome. J Am Soc Nephrol. 2005;16(4):1035-50.

5. Scully M, Goodship T. How I treat thrombotic thrombocytopenic purpura and atypical haemolytic uraemic syndrome. Br J Haematol. 2014:164:759-66.

6. Fakhouri F, Roumenina L, Provot F, Sallée M, Caillard S, Couzi L et al. Pregnancy-associated hemolytic uremic syndrome revisited in the era of complement gene mutations. J Am Soc Nephrol. 2010;21(5):859-67.

7. Dashe JS, Ramin SM, Cunningham FG. The longterm consequences of thrombotic microangiopathy (thrombotic thrombocytopenic purpura and hemolytic uremic syndrome) in pregnancy. Obstet Gynecol. 1998;91(5, Pt 1):662-8.

8. Noris M, Remuzzi G. Hemolytic uremic syndrome. J Am Soc Nephrol. 2005;16(4):1035-50.

9. Noris M, Remuzzi G. Atypical hemolytic-uremic syndrome. N Engl J Med. 2009;361(17):1676-87.
10. Saad AF, Roman J, Wyble A, Pacheco LD. Pregnancy-associated atypical hemolytic-uremic syndrome. Am J Perinatol Rep. 2016;6:e125-e128.

11. Caprioli J, Noris M, Brioschi S, Pianetti G, Castelletti F, Bettinaglio $\mathrm{P}$, et al. International Registry of Recurrent and Familial HUS/TTP. Genetics of HUS: the impact of MCP, CFH, and IF mutations on clinical presentation, response to treatment, and outcome. Blood. 2006;108(4):1267-9.

Cite this article as: Sablok A, Gupta T, Gupta S, Duggal RK, Tiwari A. Postpartum atypical haemolytic uremic syndrome: a rare clinical entity. Int J Reprod Contracept Obstet Gynecol 2019;8:3409-13. 